\title{
Evaluation of RayXpert ${ }^{\circledR}$ for shielding design of medical facilities
}

\author{
Sylvie Derreumaux ${ }^{1, *}$, Sophie Vecchiola ${ }^{1}$, Thomas Geoffray ${ }^{2}$, and Cécile Etard ${ }^{1}$ \\ ${ }^{1}$ Institut for radiation protection and nuclear safety, Radiation protection expertise department, BP17 92260 Fontenay aux Roses, \\ France \\ ${ }^{2}$ D\&S, 573 Avenue de l'Hermitage, 30200 Bagnols-sur-Cèze, France
}

\begin{abstract}
In a context of growing demands for expert evaluation concerning medical, industrial and research facilities, the French Institute for radiation protection and nuclear safety (IRSN) considered necessary to acquire new software for efficient dimensioning calculations. The selected software is RayXpert ${ }^{\circledR}$. Before using this software in routine, exposure and transmission calculations for some basic configurations were validated. The validation was performed by the calculation of gamma dose constants and tenth value layers (TVL) for usual shielding materials and for radioisotopes most used in therapy (Ir-192, Co-60 and I-131). Calculated values were compared with results obtained using MCNPX as a reference code and with published values. The impact of different calculation parameters, such as the source emission rays considered for calculation and the use of biasing techniques, was evaluated.
\end{abstract}

\section{Introduction}

For the past few years, demands for expert evaluation of medicine, industrial and research facilities dimensioning have been increasing. To respond to those requests, an efficient simulation tool is necessary. This tool should be easy to use and should offer a good compromise between calculation time and result accuracy. The software RayXpert ${ }^{\circledR}$ has been selected for this purpose.

Before using this software in routine, the impact of different calculation parameters was evaluated and basic configurations were validated.

This article describes the validation of RayXpert ${ }^{\circledR}$ for exposure and transmission calculations with the radionuclides most used in medicine for therapeutic purposes: Ir-192 and Co-60 in brachytherapy and I-131 in nuclear medicine. Preliminary results are presented.

\section{Materials and methods}

In this study, calculations and comparisons of gamma constants and tenth value layers (TVL) have been performed. Results with RayXpert ${ }^{\circledR}$ have been compared with those obtained by using MCNPX 2.7.0, that has been considered as a reference code, and with values published in the literature.

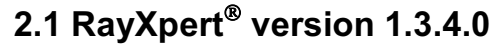

The software RayXpert ${ }^{\circledR}$ is developed by Tests and RADiations (TRAD, France). It uses Monte Carlo method implemented in GEANT 4 V10.0 to simulate photon and electron transport for energies between $1 \mathrm{keV}$ and $100 \mathrm{MeV}$. It is implemented on PC Windows and has the advantage of having a user-friendly interface that allows easy and rapid building of complex 3D geometries (Computer-Aided Design).

RayXpert $^{\circledR}$ offers the possibility of considering radioactive sources of continuous electron or photon spectra (ie: for modelling conventional radiology or radiotherapy X-ray sources).

Some important calculation parameters are automatically assessed by the software, such as the definition of the energy spectra of radionuclides' emission (database and selection of the rays), materials' composition, conversion coefficients, and the weights of the volumes for the Weight Windows variance reduction method. This enables a straightforward use of the software.

In this study, RayXpert ${ }^{\circledR}$ version 1.3.4.0 was used.

Energy spectra of radionuclides' emission are extracted from the EAF-2010 decay data library (EASY2010 system) or from the JEFF-3.1/3.1.1 radioactive decay data sub-library [1]. For this study, the EAF database was chosen as it is the default option.

Calculations take into account the emission photon rays contributing to $99 \%$ of the emitted energy, with an automatic selection by the software ("RayXpert ${ }^{\circledR}$ criterion"):

$$
\sum_{i=1}^{n \_ \text {simul }} P\left(E_{i}\right) E_{i}=0.99 \sum_{i=1}^{n \_ \text {spectrum }} P\left(E_{i}\right) E_{i}
$$

\footnotetext{
Corresponding author: sylvie.derreumaux@irsn.fr
} 
Where $P\left(E_{i}\right)$ is the radiation intensity for a given ray $i$ of energy $E_{i}, n$ simul is the number of rays that are considered for the simulation and n_spectrum is the total number of rays of the spectrum extracted from the decay data library.

The results are expressed in terms of ambient dose equivalent $\mathrm{H}^{*}(10)$. The conversion coefficients from fluence to ambient dose equivalent, $H^{*}(10)$, are automatically applied by the software and are extracted from the publication 74 of ICRP [2].

RayXpert ${ }^{\circledR}$ proposes a database of materials, whose compositions correspond to the one given in the PNNL$15870 \mathrm{rev} 1$ [3]. The choice of a given material for a given volume automatically attributes that composition to the volume.

In order to improve the convergence, different variance reduction methods are proposed as options: the Weight Windows, the thick target bremsstrahlung approximation (TTB) and distance or energy cut-off [1]. Moreover, calculation time can be reduced by the parallelization of calculations.

\subsection{MCNPX 2.7.0}

MCNPX (Monte Carlo N-Particle eXtended) is developed and maintained by the Los Alamos National Laboratory [4]. The code deals with transport of neutrons, gamma rays, and coupled transport, i.e., transport of secondary gamma rays resulting from neutron interactions. The MCNPX code can also treat the transport of electrons, both primary source electrons and secondary electrons created in gamma-ray interactions.

In this study, MCNPX version 2.7.0 was used.

Energy spectrum of the source's radiation is defined by the user. For this study, energy spectra have been extracted from ICRP 107 [5] and a selection of the most contributive rays was performed to improve calculation times, according to a home defined reference method.

The selection rule for a given ray $\mathrm{i}$ is as follows ("IRSN criterion"):

$$
\frac{P\left(E_{i}\right)}{\sum_{i} P\left(E_{i}\right)} \geq 10^{-4}
$$

Where $\mathrm{P}(\mathrm{Ei})$ is the radiation intensity for a given ray $\mathrm{i}$ (energy Ei) and $\Sigma_{\mathrm{i}} \mathrm{P}(\mathrm{Ei})$ is the sum of all intensities.

Furthermore, radiations with energy below $5 \mathrm{keV}$ were not considered because their contribution to the dose rate at a distance of $1 \mathrm{~m}$ in air is not significant.

In order to be consistent with the calculations made with RayXpert ${ }^{\circledR}$ (see 2.1), the composition of materials was also extracted from the PNNL-15870 rev 1 [3].

The photon fluence in the detector was calculated. The conversion coefficients from fluence to $H^{*}(10)$ were extracted from the ICRP 74 [2].

For this study, the convergence has been improved by the use of geometry splitting variance reduction method [4].

\subsection{Comparison between RayXpert ${ }^{\circledR}$ and MCNPX}

RayXpert $^{\circledR}$ modelling validation was performed by calculating the gamma constant and transmission through different shielding materials for Ir-192, Co-60 and I-131, the most used radioisotopes in brachytherapy and in nuclear medicine treatments, and by comparing the results obtained with RayXpert ${ }^{\circledR}$ and with MCNPX.

Calculations were performed using MCNPX with the "IRSN criterion" for the selection of the emission rays (see 2.2) and RayXpert ${ }^{\circledR}$ without biasing method.

The source was quasi punctual (sphere with a radius of $0.5 \mathrm{~mm}$ ) and in order to throw off self-attenuation, its material was set to air with a density of 0.001 . Indeed, the activity of the medical radioactive sources used is the apparent activity.

The ambient dose equivalent rate, $\dot{H}^{*}(10)$, was calculated in air at a distance of $1 \mathrm{~m}$ from the source, for a source activity of $18.5 \mathrm{GBq}$ for Ir-192 (typical activity of a new source in pulsed dose rate (PDR) brachytherapy), $3.7 \mathrm{GBq}$ for I-131 (typical activity for the treatment of thyroid cancer) and $74 \mathrm{GBq}$ for Co-60 (typical activity of a new source in high dose rate (HDR) brachytherapy). The detector was a sphere of air with a radius of $2.5 \mathrm{~cm}$.

For calculation of the gamma dose constant, $\dot{H}^{*}(10)$ was normalized to a source activity of $1 \mathrm{GBq}$.

For the calculation of transmission, the shield was a quasi-infinite wall $(10 \mathrm{~m} \times 10 \mathrm{~m} \times$ thickness $)$ centred at $50 \mathrm{~cm}$ from the source. Calculations were performed for several typical materials: ordinary concrete, steel (HT9), lead, brick (common silica) and leaded glass, with densities of $2.3,7.87,11.35,1.8$ and $6.62 \mathrm{g.cm}^{-3}$, respectively. For each material, calculations were made for thicknesses of approximately $\mathrm{n}$ tenth-value layers: $\mathrm{B}_{\mathrm{n}}=\mathrm{n} \times \mathrm{B}_{1}$ where $\mathrm{B}_{1} \sim \operatorname{TVL}(\mathrm{n}=1,2$ and 3 using MCNPX and $n=1$ and 2 using RayXpert ${ }^{\circledR}$ ).

For Ir-192 and Co-60, the $B_{1}$ values for concrete, steel and lead were obtained from TVL values for large attenuation published in the IAEA Safety Reports Series Report No. 47 [6]. For brick and leaded glass, the $B_{1}$ value for each radionuclide was determined applying an inverse density relationship to the concrete $\mathrm{B}_{1}$ value. For leaded glass, preliminary transmission calculations allowed to get a better estimation of TVL and to adjust the value of $B_{1}$ (the inverse density relationship leaded to an overestimation of TVL).

For I-131, the Ir-192 $\mathrm{B}_{1}$ values were considered, as the average emission photon energies are very close (0.36 $\mathrm{MeV}$ and $0.38 \mathrm{MeV}$ for Ir-192 and I-131, respectively).

For each radionuclide and each barrier material, the cumulative tenth-value layer, $\mathrm{TVL}_{\mathrm{c}}$, and the successive tenth-value layers, $\mathrm{TVL}_{\mathrm{n}}$ (for $\mathrm{n}=1,2 \ldots$ ), were calculated.

TVLc is the approximate TVL value for large attenuation. It was estimated as follows: for a given barrier thickness $\mathrm{B}_{\mathrm{n}}$ :

$$
T V L_{c}=-B_{n} / \log _{10}\left(T_{n}\right)
$$

Where $T_{n}$ is the transmission factor for barrier $B_{n}$ : $\mathrm{T}_{\mathrm{n}}=\mathrm{H}^{*}(10)_{\text {with }} / \mathrm{H}^{*}(10)_{\text {without, }}$, where $\mathrm{H}^{*}(10)_{\text {with }}$ and 
$H^{*}(10)_{\text {without }}$ are the ambient dose equivalent at calculation point with or without barrier, respectively.

$\mathrm{TVL}_{\mathrm{n}}$ is the $\mathrm{n}^{\text {th }}$ TVL: $\mathrm{TVL}_{1}$ is the $1^{\text {rst }} \mathrm{TVL}, \mathrm{TVL}_{2}$ is the $2^{\text {nd }}$ TVL... It was estimated as follows: for two successive barrier thicknesses $B_{n-1}$ and $B_{n}$ :

$$
T V L_{n}=-\left(B_{n}-B_{n-1}\right) / \log _{10}\left(T_{n} / T_{n-1}\right)
$$

\subsection{Influence of the ray selection rule}

In order to evaluate the influence of the RayXpert ${ }^{\circledR}$ selection rule for the photon emission rays, ambient dose equivalent rate, $\dot{\mathrm{H}}^{*}(10)$, was calculated using MCNPX and energy spectra obtained with the RayXpert ${ }^{\circledR}$ criterion (paragraph 2.1) on the one hand, and with the IRSN criterion on the other hand (paragraph 2.2).

Calculations were performed in air at a distance of $1 \mathrm{~m}$ from the source, without shield and with a shield of different materials and thicknesses, for an Ir-192 source of $18.5 \mathrm{GBq}$ and for an I-131 source of $3.7 \mathrm{GBq}$.

\subsection{Impact of the use of biasing technics}

In order to evaluate the impact of biasing technics proposed by RayXpert ${ }^{\circledR}$, ambient dose equivalent rate $\dot{\mathrm{H}}^{*}(10)$ was calculated for Ir-192 using TTB approximation and energy cut-off, either separately or jointly, for different shielding materials and different thicknesses. When applied, the energy cut-off values were $10 \mathrm{keV}$ for photons and $100 \mathrm{keV}$ for electrons.

\section{Results and discussion}

\subsection{Gamma dose constant}

For each radionuclide, the gamma dose constant was obtained by the calculation of $\dot{\mathrm{H}}^{*}(10)$ at a distance of 1 meter from the source in air and without barrier. Results are presented in table 1, together with published data.

There is an excellent agreement between RayXpert ${ }^{\circledR}$ and MCNPX for Ir-192 and Co-60, with calculated values of 138 and $139 \mu \mathrm{Sv} \cdot \mathrm{m}^{2} \cdot \mathrm{h}^{-1} \cdot \mathrm{GBq}^{-1}$ for Ir-192 and 340 and $341 \mu \mathrm{Sv} \cdot \mathrm{m}^{2} \cdot \mathrm{h}^{-1} \cdot \mathrm{GBq}^{-1}$ for Co-60, with RayXpert $^{\circledR}$ and MCNPX, respectively. However, a significant difference $(\sim 9 \%)$ appears for I-131, with values of 60 and $66 \mu \mathrm{Sv} \cdot \mathrm{m}^{2} \cdot \mathrm{h}^{-1} \cdot \mathrm{GBq}^{-1}$, using respectively RayXpert ${ }^{\circledR}$ and MCNPX.

Considering the statistical uncertainties, the values obtained by MCNPX are in good agreement with the exposure values published in 2004 by Delacroix et al. for a distance of 1 meter from a punctual source [7]: 135, 66 and $351 \mu \mathrm{Sv} \cdot \mathrm{m}^{2} \cdot \mathrm{h}^{-1} \cdot \mathrm{GBq}^{-1}$, respectively for Ir-192, I-131 and Co-60. For I-131, the gamma dose constant calculated by MCNPX corresponds to the value recommended by the DIN 6844-3 standard [8]. On the contrary, the results are quite different from the values published in 1981 by the Oak Ridge National Laboratory [9]: $159.9,76.5$ and $370.3 \mu \mathrm{Sv} \cdot \mathrm{m}^{2} \cdot \mathrm{h}^{-1} \cdot \mathrm{GBq}^{-1}$, respectively for Ir-192, I-131 and Co-60.
Table 1. Gamma dose constant calculated with MCNPX and RayXpert ${ }^{\circledR}$ for Ir-192, I-131 and Co-60, and data published by Delacroix [7], DIN [8] and ORNL [9]. Relative statistical uncertainties are shown in brackets as percentages.

\begin{tabular}{|c|c|c|c|c|c|}
\hline \multirow[b]{2}{*}{$\begin{array}{l}\text { Radio- } \\
\text { nuclide }\end{array}$} & \multicolumn{5}{|c|}{$\begin{array}{c}\text { Gamma dose constant } \\
\left(\mu \mathrm{Sv} \cdot \mathrm{m}^{2} \cdot \mathrm{h}^{-1} \cdot \mathrm{GBq}^{-1}\right)\end{array}$} \\
\hline & $\underset{\text { Xpert }^{\circledR}}{\text { Ray- }}$ & MCNPX & Delacroix & $\begin{array}{c}\text { DIN } \\
6844- \\
3\end{array}$ & ORNL \\
\hline Ir-192 & $138(1$ & $139(2.0)$ & 135 & & 159.9 \\
\hline I-131 & $60(0.7)$ & $66(0.9)$ & 66 & 66 & 76.5 \\
\hline Co-60 & 340 (1.9) & 341 (1.9) & 351 & & 370.3 \\
\hline
\end{tabular}

\subsection{Transmission and TVL}

Transmission was calculated for a sample of shields (materials and thicknesses). For each radionuclide, $\dot{\mathrm{H}}^{*}(10)$ was calculated at a distance of 1 meter from the source in air, with and without barrier. Results are presented in tables 2, 3 and 4 for Ir-192, I-131 and Co-60, respectively.

There is an overall good agreement between RayXpert $^{\circledR}$ and MCNPX regarding transmission calculation: the relative difference between transmitted $\dot{\mathrm{H}}^{*}(10)$ is lower than $10 \%$ for the three radionuclides and all the barriers. The discrepancies are included in the calculation uncertainty $(2 \sigma)$, except perhaps for one configuration (I-131, $40 \mathrm{~cm}$ brick).

Using the results obtained for transmission calculation, $\mathrm{TVL}_{\mathrm{c}}$ and $\mathrm{TVL}_{\mathrm{n}}$ were estimated according to formulae (3) and (4). Results are presented in tables 5, 6 and 7 for Ir-192, I-131 and Co-60, respectively.

For each radionuclide and each barrier material, $\mathrm{TVL}_{\mathrm{c}}$ was calculated using transmission factor for the largest barrier that could be simulated given the calculation time: with MCNPX: $\mathrm{B}_{3}$ for I-192 and I-131 and $\mathrm{B}_{2}$ for Co-60; with RayXpert ${ }^{\circledR}: B_{2}$. In order to compare the results, TVLc was also calculated using transmission factor for thickness $\mathrm{B}_{2}$ with MCNPX for I-192 and I-131.

The successive tenth-value layers, $\mathrm{TVL}_{\mathrm{n}}$, were evaluated using the transmission factors for successive barrier thicknesses: $\mathrm{TVL}_{1}$ and $\mathrm{TVL}_{2}$ with RayXpert ${ }^{\mathrm{B}}$, $\mathrm{TVL}_{1}, \mathrm{TVL}_{2}$ and $\mathrm{TVL}_{3}$ with MCNPX.

The $\mathrm{TVL}_{\mathrm{c}}$ and $\mathrm{TVL}_{\mathrm{n}}$ values calculated with RayXpert ${ }^{\circledR}$ are in very good agreement with those obtained with MCNPX: the difference is globally lower than $5 \%$.

As expected, $\mathrm{TVL}_{2}$ is lower than $\mathrm{TVL}_{1}$ for concrete, steel and brick, for the three radionuclides, due to the build-up effect. On the contrary, $\mathrm{TVL}_{2}$ is higher than $\mathrm{TVL}_{1}$ for lead and leaded glass (except for Co-60), due to radiation hardening while penetrating the barrier (photoelectric effect for low energy photons).

Regarding Ir-192, the $\mathrm{TVL}_{\mathrm{c}}$ values obtained with MCNPX for the largest barrier thickness $\left(\mathrm{B}_{3}\right)$ are very close or equal to the TVL published by the IAEA SRS Report No. 47 for large attenuation $(15.2 \mathrm{~cm}, 1.6 \mathrm{~cm}$ and $4.3 \mathrm{~cm}$, respectively for ordinary concrete, lead and steel) [6]. Also, $\mathrm{TVL}_{1}$ for steel matches the value recommended by IAEA $(4.9 \mathrm{~cm})$. 
Table 2. Transmission calculated with MCNPX and RayXpert ${ }^{\circledR}$ for Ir-192 (18.5 GBq), and relative difference $(\Delta)$. Relative statistical errors $(1 \sigma)$ are shown in brackets $(\%)$.

\begin{tabular}{|c|c|c|c|c|}
\hline \multicolumn{2}{|c|}{ Barrier } & \multicolumn{2}{|c|}{$\begin{array}{l}\dot{\mathbf{H}}^{*}(\mathbf{1 0}) \\
(\mathrm{Sv} / \mathrm{h}) \\
\end{array}$} & \multirow[t]{2}{*}{$\begin{array}{c}\Delta \\
(\%) \\
\end{array}$} \\
\hline Material & $\begin{array}{c}B_{n} \\
(\mathrm{~cm})\end{array}$ & RayXpert $^{\circledR}$ & MCNPX & \\
\hline Air & - & $2.55 \mathrm{E}-03(1.3)$ & $2.56 \mathrm{E}-03(2.0)$ & -0.5 \\
\hline \multirow{3}{*}{ Concrete } & 15 & $4.21 \mathrm{E}-04(3.1)$ & $4.45 \mathrm{E}-04(2.4)$ & -5.4 \\
\hline & 30 & 3.77E-05 (3.9) & $4.03 \mathrm{E}-05(1.1)$ & -6.5 \\
\hline & 45 & - & $3.20 \mathrm{E}-06(1.3)$ & - \\
\hline \multirow{3}{*}{ Lead } & 1.5 & $1.27 \mathrm{E}-04(3.5)$ & $1.38 \mathrm{E}-04(3.1)$ & -7.7 \\
\hline & 3 & $1.52 \mathrm{E}-05(5.1)$ & $1.54 \mathrm{E}-05(8.4)$ & -1.6 \\
\hline & 4.5 & - & $2.31 \mathrm{E}-06(2.8)$ & - \\
\hline \multirow{3}{*}{ Steel } & 5 & $2.51 \mathrm{E}-04(2.1)$ & $2.48 \mathrm{E}-04(2.2)$ & 1.3 \\
\hline & 10 & $1.54 \mathrm{E}-05(5.4)$ & $1.52 \mathrm{E}-05(1.6)$ & 1.3 \\
\hline & 15 & - & 8.99E-07 (0.8) & - \\
\hline \multirow{3}{*}{ Brick } & 20 & 4.41E-04 (1.0) & $4.40 \mathrm{E}-04(2.5)$ & 0.1 \\
\hline & 40 & $3.86 \mathrm{E}-05(2.5)$ & $3.78 \mathrm{E}-05(0.8)$ & 2.2 \\
\hline & 60 & - & $3.08 \mathrm{E}-06(1.8)$ & - \\
\hline \multirow{3}{*}{$\begin{array}{l}\text { Leaded } \\
\text { glass }\end{array}$} & 3 & $1.45 \mathrm{E}-04(2.2)$ & $1.56 \mathrm{E}-04(2.6)$ & -7.3 \\
\hline & 6 & $1.77 \mathrm{E}-05(5.0)$ & $1.78 \mathrm{E}-05(4.3)$ & -0.4 \\
\hline & 12 & - & $3.66 \mathrm{E}-07(5.1)$ & - \\
\hline
\end{tabular}

Table 3. Transmission calculated with MCNPX and RayXpert ${ }^{\circledR}$ for I-131 (3.7 GBq), and relative difference $(\Delta)$. Relative statistical errors $(1 \sigma)$ are shown in brackets $(\%)$.

\begin{tabular}{|c|c|c|c|c|}
\hline \multicolumn{2}{|c|}{ Barrier } & \multicolumn{2}{|c|}{$\begin{array}{l}\dot{\mathbf{H}}^{*}(10) \\
(\mathrm{Sv} / \mathrm{h})\end{array}$} & \multirow[t]{2}{*}{$\begin{array}{c}\Delta \\
(\%)\end{array}$} \\
\hline Material & $\begin{array}{c}B_{n} \\
(\mathbf{c m})\end{array}$ & RayXpert $^{\circledR}$ & MCNPX & \\
\hline Air & - & $2.23 \mathrm{E}-04(0.7)$ & $2.45 \mathrm{E}-04(0.9)$ & -9.0 \\
\hline \multirow{3}{*}{ Concrete } & 15 & 4.13E-05 (2.1) & 4.16E-05 (1.9) & -0.7 \\
\hline & 30 & $3.89 \mathrm{E}-06(2.8)$ & $3.89 \mathrm{E}-06(0.3)$ & 0.0 \\
\hline & 45 & - & $3.16 \mathrm{E}-07(0.3)$ & - \\
\hline \multirow{3}{*}{ Lead } & 1.5 & $1.17 \mathrm{E}-05(2.9)$ & $1.16 \mathrm{E}-05(2.4)$ & 0.6 \\
\hline & 3 & $1.73 \mathrm{E}-06(2.9)$ & $1.77 \mathrm{E}-06(2.1)$ & -2.5 \\
\hline & 4.5 & - & $3.27 \mathrm{E}-07(2.0)$ & - \\
\hline \multirow{3}{*}{ Steel } & 5 & $2.37 \mathrm{E}-05(2.0)$ & $2.40 \mathrm{E}-05(0.9)$ & -1.3 \\
\hline & 10 & $1.33 \mathrm{E}-06(4.0)$ & $1.45 \mathrm{E}-06(0.6)$ & -8.4 \\
\hline & 15 & - & $8.93 \mathrm{E}-08(0.6)$ & - \\
\hline \multirow{3}{*}{ Brick } & 20 & $4.08 \mathrm{E}-05(2.0)$ & $4.10 \mathrm{E}-05(0.2)$ & -0.5 \\
\hline & 40 & $3.95 \mathrm{E}-06(3.1)$ & $3.64 \mathrm{E}-06(0.3)$ & 8.5 \\
\hline & 60 & - & $2.93 \mathrm{E}-07(0.3)$ & - \\
\hline \multirow{3}{*}{$\begin{array}{l}\text { Leaded } \\
\text { glass }\end{array}$} & 3 & $1.34 \mathrm{E}-05(2.1)$ & $1.40 \mathrm{E}-05(2.8)$ & -4.6 \\
\hline & 6 & $1.86 \mathrm{E}-06(3.9)$ & $2.03 \mathrm{E}-06(4.3)$ & -8.6 \\
\hline & 12 & - & $6.36 \mathrm{E}-08$ (3.7) & - \\
\hline
\end{tabular}

Table 4. Transmission calculated with MCNPX and RayXpert ${ }^{\circledR}$ for Co-60 (74 GBq), and relative difference $(\Delta)$. Relative statistical errors $(1 \sigma)$ are shown in brackets $(\%)$

\begin{tabular}{|c|c|c|c|c|}
\hline \multicolumn{2}{|c|}{ Barrier } & \multicolumn{2}{c|}{$\begin{array}{c}\dot{\mathbf{H}}^{*}(\mathbf{1 0 )} \\
(\mathbf{S v} / \mathbf{h})\end{array}$} & $\begin{array}{c}\Delta \\
(\%)\end{array}$ \\
\hline \multirow{2}{*}{ Material } & $\begin{array}{c}\mathbf{B}_{\mathbf{n}} \\
(\mathbf{c m})\end{array}$ & RayXpert $^{\circledR}$ & MCNPX & \\
\hline Air & - & $2.52 \mathrm{E}-02(1.9)$ & $2.53 \mathrm{E}-02(1.9)$ & -0.4 \\
\hline \multirow{2}{*}{ Concrete } & 25 & $3.67 \mathrm{E}-03(1.4)$ & $3.55 \mathrm{E}-03(2.0)$ & 3.4 \\
\cline { 2 - 5 } & 50 & $2.83 \mathrm{E}-04(4.7)$ & $2.70 \mathrm{E}-04(1.2)$ & 4.7 \\
\hline \multirow{2}{*}{ Lead } & 4 & $3.61 \mathrm{E}-03(1.5)$ & $3.58 \mathrm{E}-03(1.0)$ & 0.8 \\
\cline { 2 - 5 } & 8 & $4.12 \mathrm{E}-04(4.5)$ & $3.77 \mathrm{E}-04(0.6)$ & 9.3 \\
\hline \multirow{2}{*}{ Steel } & 8 & $3.13 \mathrm{E}-03(1.7)$ & $3.16 \mathrm{E}-03(1.8)$ & -0.9 \\
\cline { 2 - 5 } & 16 & $2.09 \mathrm{E}-04(5.8)$ & $2.07 \mathrm{E}-04(1.0)$ & 0.8 \\
\hline \multirow{2}{*}{ Brick } & 30 & $4.51 \mathrm{E}-03(1.2)$ & $4.40 \mathrm{E}-03(1.4)$ & 2.5 \\
\cline { 2 - 5 } & 60 & $4.44 \mathrm{E}-04(3.7)$ & $4.33 \mathrm{E}-04(0.3)$ & 2.5 \\
\hline \multirow{2}{*}{$\begin{array}{c}\text { Leaded } \\
\text { glass }\end{array}$} & 8 & $3.14 \mathrm{E}-03(2.4)$ & $3.20 \mathrm{E}-03(1.0)$ & -1.9 \\
\cline { 2 - 5 } & 16 & $2.70 \mathrm{E}-04(3.9)$ & $2.76 \mathrm{E}-04(0.6)$ & -2.3 \\
\hline
\end{tabular}

Table 5. $\mathrm{TVL}_{\mathrm{c}}$ and $\mathrm{TVL}_{\mathrm{n}}$ calculated using the transmission factors obtained with MCNPX and RayXpert ${ }^{\circledR}$ for Ir-192.

\begin{tabular}{|c|c|c|c|c|c|}
\hline \multicolumn{2}{|c|}{ Barrier } & \multicolumn{2}{|c|}{$\mathrm{TVL}_{\mathrm{c}}(\mathrm{cm})$} & \multicolumn{2}{|c|}{$T_{V L}(\mathrm{~cm})$} \\
\hline Material & $\begin{array}{c}\mathrm{B}_{\mathrm{n}} \\
(\mathrm{cm})\end{array}$ & $\begin{array}{c}\text { Ray- } \\
\text { Xpert }^{\circledR}\end{array}$ & $\begin{array}{c}\text { MCNP- } \\
\text { X }\end{array}$ & $\begin{array}{c}\text { Ray- } \\
\text { Xpert }^{\circledR}\end{array}$ & $\begin{array}{c}\text { MCNP- } \\
\mathrm{X}\end{array}$ \\
\hline \multirow{3}{*}{ Concrete } & 15 & - & - & 19.2 & 19.7 \\
\hline & 30 & 16.4 & 16.6 & 14.3 & 14.4 \\
\hline & 45 & - & 15.5 & - & 13.6 \\
\hline \multirow{3}{*}{ Lead } & 1.5 & - & - & 1.2 & 1.2 \\
\hline & 3 & 1.3 & 1.4 & 1.6 & 1.6 \\
\hline & 4.5 & - & 1.5 & - & 1.8 \\
\hline \multirow{3}{*}{ Steel } & 5 & - & - & 5.0 & 4.9 \\
\hline & 10 & 4.5 & 4.5 & 4.1 & 4.1 \\
\hline & 15 & - & 4.3 & - & 4.1 \\
\hline \multirow{3}{*}{ Brick } & 20 & - & - & 26.2 & 26.1 \\
\hline & 40 & 22.0 & 21.8 & 18.9 & 18.7 \\
\hline & 60 & - & 20.5 & - & 18.4 \\
\hline \multirow{3}{*}{$\begin{array}{l}\text { Leaded } \\
\text { glass }\end{array}$} & 3 & - & - & 2.4 & 2.5 \\
\hline & 6 & 2.8 & 2.8 & 3.3 & 3.2 \\
\hline & 12 & - & 3.1 & - & 3.6 \\
\hline
\end{tabular}

Table 6. $\mathrm{TVL}_{\mathrm{c}}$ and $\mathrm{TVL}_{\mathrm{n}}$ calculated using the transmission factors obtained with MCNPX and RayXpert ${ }^{\circledR}$ for I-131.

\begin{tabular}{|c|c|c|c|c|c|}
\hline \multicolumn{2}{|c|}{ Barrier } & \multicolumn{2}{|c|}{$\mathrm{TVL}_{\mathrm{c}}(\mathrm{cm})$} & \multicolumn{2}{|c|}{$T_{V L}(\mathrm{~cm})$} \\
\hline Material & $\begin{array}{c}\mathrm{B}_{\mathrm{n}} \\
(\mathrm{cm})\end{array}$ & $\begin{array}{c}\text { Ray- } \\
\text { Xpert }^{\circledR}\end{array}$ & $\begin{array}{c}\text { MCNP- } \\
\mathrm{X}\end{array}$ & $\begin{array}{c}\text { Ray- } \\
\text { Xpert }^{\circledR}\end{array}$ & $\begin{array}{c}\text { MCNP- } \\
\text { X }\end{array}$ \\
\hline \multirow{3}{*}{ Concrete } & 15 & - & - & 20.5 & 19.5 \\
\hline & 30 & 17.1 & 16.7 & 14.6 & 14.6 \\
\hline & 45 & - & 15.6 & - & 13.8 \\
\hline \multirow{3}{*}{ Lead } & 1.5 & - & - & 1.2 & 1.1 \\
\hline & 3 & 1.4 & 1.4 & 1.8 & 1.8 \\
\hline & 4.5 & - & 1.6 & - & 2.0 \\
\hline \multirow{3}{*}{ Steel } & 5 & - & - & 5.1 & 5.0 \\
\hline & 10 & 4.5 & 4.5 & 4.0 & 4.1 \\
\hline & 15 & - & 4.4 & - & 4.1 \\
\hline \multirow{3}{*}{ Brick } & 20 & - & - & 27.1 & 25.8 \\
\hline & 40 & 22.8 & 21.9 & 19.7 & 19.0 \\
\hline & 60 & - & 20.5 & - & 18.3 \\
\hline \multirow{3}{*}{$\begin{array}{l}\text { Leaded } \\
\text { glass }\end{array}$} & 3 & - & - & 2.5 & 2.4 \\
\hline & 6 & 2.9 & 2.9 & 3.5 & 3.6 \\
\hline & 12 & 3.4 & 3.3 & 4.1 & 4.0 \\
\hline
\end{tabular}

Table 7. $\mathrm{TVL}_{\mathrm{c}}$ and $\mathrm{TVL}_{\mathrm{n}}$ calculated using the transmission factors obtained with MCNPX and RayXpert ${ }^{\circledR}$ for Co-60.

\begin{tabular}{|c|c|c|c|c|c|}
\hline \multicolumn{2}{|c|}{ Barrier } & \multicolumn{2}{|c|}{$\mathrm{TVL}_{\mathrm{c}}(\mathrm{cm})$} & \multicolumn{2}{|c|}{$\operatorname{TVL}_{\mathrm{n}}(\mathrm{cm})$} \\
\hline Material & $\begin{array}{c}B_{n} \\
(\mathrm{~cm})\end{array}$ & $\begin{array}{c}\text { Ray- } \\
\text { Xpert }^{\circledR}\end{array}$ & $\begin{array}{l}\text { MCNP- } \\
\quad \mathrm{X}\end{array}$ & $\begin{array}{c}\text { Ray- } \\
\text { Xpert }^{(B)}\end{array}$ & $\begin{array}{c}\text { MCNP- } \\
\text { X }\end{array}$ \\
\hline \multirow{2}{*}{ Concrete } & 25 & - & - & 29.9 & 29.3 \\
\hline & 50 & 25.6 & 25.4 & 22.5 & 22.3 \\
\hline \multirow{2}{*}{ Lead } & 4 & - & - & 4.7 & 4.7 \\
\hline & 8 & 4.5 & 4.4 & 4.2 & 4.1 \\
\hline \multirow{2}{*}{ Steel } & 8 & - & - & 8.8 & 8.9 \\
\hline & 16 & 7.7 & 7.7 & 6.8 & 6.8 \\
\hline \multirow{2}{*}{ Brick } & 30 & - & - & 40.2 & 39.5 \\
\hline & 60 & 34.2 & 34.0 & 29.8 & 29.8 \\
\hline \multirow{2}{*}{$\begin{array}{l}\text { Leaded } \\
\text { glass }\end{array}$} & 8 & - & - & 8.9 & 8.9 \\
\hline & 16 & 8.1 & 8.2 & 7.5 & 7.5 \\
\hline
\end{tabular}


Concerning Co-60, the TVLc values obtained with RayXpert $^{\circledR}$ and MCNPX for the barrier thickness B2 are consistent with the IAEA TVL $(21.8 \mathrm{~cm}, 4.1 \mathrm{~cm}$ and $7.1 \mathrm{~cm}$, respectively for ordinary concrete, lead and steel); however they are higher than the IAEA values, suggesting that these correspond to thicknesses larger than B2. TVL1 for steel match the value recommended by IAEA $(8.7 \mathrm{~cm})$, while TVL1 for concrete are significantly higher $(29.9 \mathrm{~cm}$ and $29.3 \mathrm{~cm}$ versus $24.5 \mathrm{~cm})$.

Significant discrepancies appear between our results and the TVL1 and $\mathrm{TVL}_{\mathrm{e}}$ values published by Delacroix for lead and steel $\left(\mathrm{TVL}_{\mathrm{e}}\right.$ is the equilibrium TVL; it can be approximated by $\mathrm{TVL}_{3}$ ). The Delacroix et al. data are systematically higher, for the three radionuclides, especially the TVL $\mathrm{T}_{1}$ values: $2.6 \mathrm{~cm}, 2.4 \mathrm{~cm}$ and $6.6 \mathrm{~cm}$ for Ir-192, I-131 and Co-60, respectively, for lead; $7.8 \mathrm{~cm}, 7.7 \mathrm{~cm}$ and $10.3 \mathrm{~cm}$ for Ir-192, I-131 and Co-60, respectively, for steel [7].

\subsection{Influence of the ray selection rule and of the automatic energy distribution of the results}

Ambient dose equivalent rate, $\dot{\mathrm{H}}^{*}(10)$, was calculated using MCNPX and emission energy spectra obtained with the RayXpert ${ }^{\circledR}$ selection criterion on the one hand, and with the IRSN criterion on the other hand, for Ir-192 and I-131 and for different barrier materials and thicknesses. Results are presented in tables 8 and 9 for Ir-192 and I-131, respectively.

The relative difference between $\dot{H}^{*}(10)$ calculated with the IRSN criterion and with the RayXpert ${ }^{\circledR}$ criterion is lower than $5 \%$ and is included in the calculation uncertainty $(2 \sigma)$, for Ir-192 and I-131. The average relative difference is lower than $1 \%(0.0 \%$ for $\operatorname{Ir}-192$ and $-0.4 \%$ for I-131).

It appears that the RayXpert ${ }^{\circledR}$ automatic selection rule for the emission photon rays does not impact significantly the calculated ambient dose equivalent rate for Ir-192 and I-131.

For I-131, the relative difference between $\mathrm{H}^{*}(10)$ calculated with both criteria and without barrier is only $-2.1 \%$. This cannot explain the significant difference obtained for the gamma dose constant calculated with RayXpert $^{(\mathbb{R}}$ and MCNPX (see 3.1). As calculations with MCNPX were performed using the ICRP 107 emission spectrum, calculations were also made using the EAF2010 spectrum with MCNPX, with both selection criteria. This gave the same results as using the ICRP 107 emission spectrum $(2.46 \mathrm{E}-04 \mathrm{~Sv} / \mathrm{h}$ with IRSN criterion and 2.39E-04 Sv/h with RayXpert criterion). However, again a small difference $(-2.8 \%)$ appears between the results obtained with both criterion, suggesting that the RayXpert ${ }^{\circledR}$ selection criteria could explain partially the difference between the gamma dose constant calculated with RayXpert ${ }^{\circledR}$ and MCNPX.

The emission photon rays that were considered for simulation using the different approaches are shown in figure 1. It can be seen that the RayXpert ${ }^{\circledR}$ criterion (RXT) strongly reduces the number of rays considered for the simulation, irrespective of the emission spectrum
(ICRP 107 or EAF-2010) or of the software (RayXpert ${ }^{\circledR}$ or MCNPX). The removed rays correspond to the lowest energies or to the lowest intensities with intermediate energies.

Table 8. $\dot{H}^{*}(10)$ calculated with MCNPX for Ir-192 with IRSN and RayXpert ${ }^{\circledR}$ criteria for selection of the photon emission rays, and relative difference $(\Delta)$. Relative statistical uncertainties $(1 \sigma)$ are shown in brackets as percentages.

\begin{tabular}{|c|c|c|c|c|}
\hline \multicolumn{2}{|c|}{ Barrier } & \multicolumn{2}{|c|}{$\begin{array}{l}\dot{\text { H}} *(10) \\
(\mathrm{Sv} / \mathrm{h})\end{array}$} & \multirow[t]{2}{*}{$\begin{array}{c}\Delta \\
(\%)\end{array}$} \\
\hline Material & $\begin{array}{l}\mathrm{B}_{\mathrm{n}} \\
(\mathrm{cm})\end{array}$ & $\begin{array}{l}\text { IRSN } \\
\text { criterion }\end{array}$ & $\begin{array}{c}\text { RayXpert }{ }^{\circledR} \\
\text { criterion }\end{array}$ & \\
\hline Air & - & $2.56 \mathrm{E}-03(2.0)$ & $2.56 \mathrm{E}-03(2.0)$ & 0.1 \\
\hline \multirow{3}{*}{ Concrete } & 15 & $4.45 \mathrm{E}-04(2.4)$ & $4.40 \mathrm{E}-04(6.1)$ & -1.1 \\
\hline & 30 & $4.03 \mathrm{E}-05(1.1)$ & $4.05 \mathrm{E}-05(1.1)$ & 0.4 \\
\hline & 45 & $3.20 \mathrm{E}-06(1.3)$ & $3.25 \mathrm{E}-06(0.9)$ & 1.7 \\
\hline \multirow{3}{*}{ Lead } & 1.5 & $1.38 \mathrm{E}-04(3.1)$ & $1.32 \mathrm{E}-04(3.1)$ & -4.1 \\
\hline & 3 & $1.54 \mathrm{E}-05(8.4)$ & $1.54 \mathrm{E}-05(2.0)$ & 0.0 \\
\hline & 4.5 & $2.31 \mathrm{E}-06(2.8)$ & $2.32 \mathrm{E}-06(3.2)$ & 0.5 \\
\hline \multirow{3}{*}{ Steel } & 5 & $2.48 \mathrm{E}-04(2.2)$ & $2.56 \mathrm{E}-04(3.0)$ & 3.4 \\
\hline & 10 & $1.52 \mathrm{E}-05(1.6)$ & $1.51 \mathrm{E}-05(1.5)$ & -0.6 \\
\hline & 15 & $8.99 \mathrm{E}-07(0.8)$ & 8.99E-07 (0.8) & 0.0 \\
\hline
\end{tabular}

Table 9. $\dot{H}^{*}(10)$ calculated with MCNPX for I-131 with IRSN and RayXpert ${ }^{\circledR}$ criteria for selection of the photon emission rays, and relative difference $(\Delta)$. Relative statistical uncertainties $(1 \sigma)$ are shown in brackets as percentages.

\begin{tabular}{|c|c|c|c|c|}
\hline \multicolumn{2}{|c|}{ Barrier } & \multicolumn{2}{|c|}{$\begin{array}{l}\dot{\mathbf{H}}^{*}(\mathbf{1 0}) \\
(\mathrm{Sv} / \mathbf{h})\end{array}$} & \multirow[t]{2}{*}{$\begin{array}{c}\Delta \\
(\%) \\
\end{array}$} \\
\hline Material & $\begin{array}{c}\mathrm{B}_{\mathrm{n}} \\
(\mathrm{cm})\end{array}$ & $\begin{array}{c}\text { IRSN } \\
\text { criterion }\end{array}$ & $\begin{array}{c}\text { RayXpert }^{\circledR} \\
\text { criterion }^{\circledR}\end{array}$ & \\
\hline Air & - & $2.45 \mathrm{E}-04(0.9)$ & $2.40 \mathrm{E}-04(0.9)$ & -2.1 \\
\hline \multirow{3}{*}{ Concrete } & 15 & $4.16 \mathrm{E}-05(1.9)$ & $4.19 \mathrm{E}-05(1.8)$ & 0.7 \\
\hline & 30 & $3.89 \mathrm{E}-06(0.3)$ & $3.88 \mathrm{E}-06(0.3)$ & -0.3 \\
\hline & 45 & $3.16 \mathrm{E}-07(0.3)$ & $3.14 \mathrm{E}-07(0.3)$ & -0.6 \\
\hline \multirow{3}{*}{ Lead } & 1.5 & $1.16 \mathrm{E}-05(2.4)$ & $1.21 \mathrm{E}-05(2.3)$ & 4.5 \\
\hline & 3 & $1.77 \mathrm{E}-06(2.1)$ & $1.74 \mathrm{E}-06(2.1)$ & -1.8 \\
\hline & 4.5 & $3.27 \mathrm{E}-07(2.0)$ & $3.27 \mathrm{E}-07(2.0)$ & 0.0 \\
\hline \multirow{3}{*}{ Steel } & 5 & $2.40 \mathrm{E}-05(0.9)$ & $2.35 \mathrm{E}-05(0.9)$ & -2.0 \\
\hline & 10 & $1.45 \mathrm{E}-06(0.6)$ & $1.44 \mathrm{E}-06(0.6)$ & -0.7 \\
\hline & 15 & $8.93 \mathrm{E}-08(0.6)$ & $8.81 \mathrm{E}-08(0.6)$ & -1.3 \\
\hline
\end{tabular}

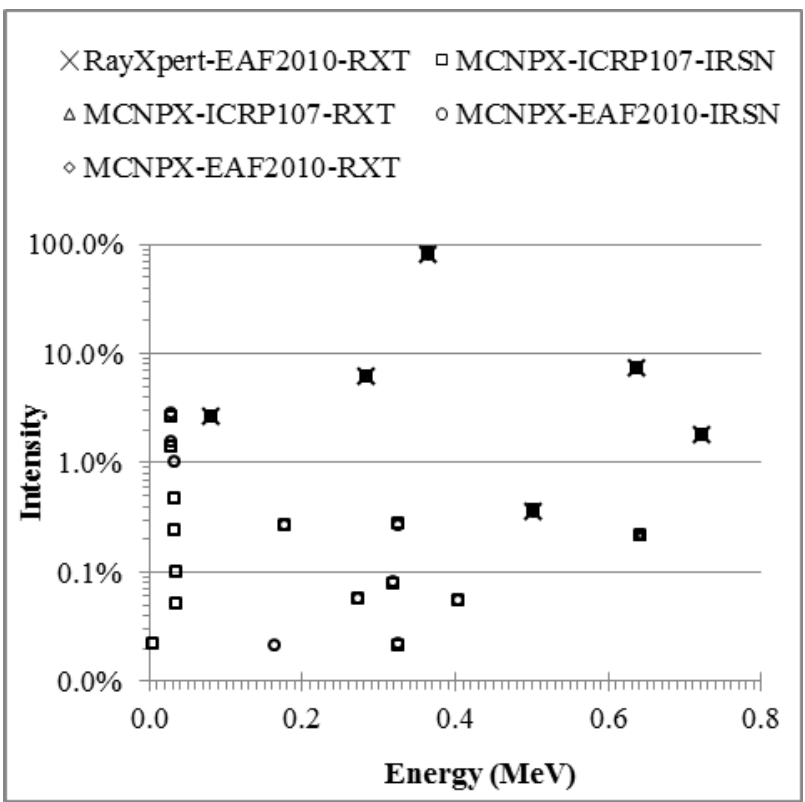

Figure 1. Emission photon rays that were considered for simulation using the different approaches. 
Further investigations have been performed with RayXpert ${ }^{\circledR}$, regarding the automatic energy distribution of the results. Indeed, the software distributes the calculated fluences as a histogram with energy bins automatically determined: the energy binning is logarithmic, with 10 steps per decade (default option). Fluences are converted to $\mathrm{H}^{*}(10)$ using the conversion coefficients from the publication 74 of ICRP [2] (paragraph 2.1). As the software offers to the user the possibility to define any energy distribution (input file), simulations were also made (calculations in air without barrier) using the energy steps of the ICRP 74 A.21 table. For I-131, the calculated value for $\mathrm{H}^{*}(10)$ was $2.38 \mathrm{E}-04$ $\mathrm{Sv} / \mathrm{h}( \pm 0.7 \%)$.

The significant increase of the $\mathrm{H}^{*}(10)$ value $(+7 \%)$ using the ICRP 74 energy steps instead of the default option for the energy distribution (see table 3) can explain the difference observed for the gamma dose constant calculated with RayXpert ${ }^{(B}$ and MCNPX, if this effect is added to the small impact of the ray selection rule $(\sim 2-3 \%)$. Note that the simulations with MCNPX were made using the ICRP 74 energy steps for the conversion coefficients (calculation of $\mathrm{H}^{*}(10)$ with tally F4).

\subsection{Impact of the use of biasing technics}

$\dot{\mathrm{H}}^{*}(10)$ was calculated for Ir-192 using TTB approximation and energy cut-off, either separately or jointly, with concrete, lead and steel barrier. Results are presented in table 10 for barrier thickness $B_{1}(15 \mathrm{~cm}, 1.5$ $\mathrm{cm}$ and $5 \mathrm{~cm}$ for concrete, lead and steel, respectively).

The use of biasing methods in RayXpert ${ }^{\circledR}$ reduces significantly the calculation time and/or the statistical error, with a relative difference in $\dot{\mathrm{H}}^{*}(10)$ (between results obtained with and without biasing method) lower than $10 \%$, which is acceptable for radiation protection purposes.

Table 10. $\dot{H}^{*}(10)$ calculated with RayXpert ${ }^{\circledR}$ for Ir-192 and a barrier of thickness $\mathrm{B}_{1}$, with and without biasing methods (TTB approximation and energy cut-off), statistical errors, relative difference $(\Delta)$ (with and without biasing) and calculation times.

\begin{tabular}{|c|c|c|c|c|c|}
\hline $\begin{array}{c}\text { Barrier } \\
\text { material }\end{array}$ & $\begin{array}{c}\text { Biasing } \\
\text { method }\end{array}$ & $\begin{array}{c}\dot{\mathbf{H}}^{*} \mathbf{( 1 0 )} \\
\mathbf{( S v} / \mathbf{h})\end{array}$ & $\begin{array}{c}\text { Error } \\
\mathbf{( \% )}\end{array}$ & $\begin{array}{c}\Delta \\
\mathbf{( \% )}\end{array}$ & $\begin{array}{c}\text { Time } \\
\mathbf{( h )}\end{array}$ \\
\hline \multirow{4}{*}{ Concrete } & No bias & $4.21 \mathrm{E}-04$ & 3.1 & - & 6.4 \\
\cline { 2 - 6 } & TTB & $4.55 \mathrm{E}-04$ & 2.9 & 8.0 & 1.1 \\
\cline { 2 - 6 } & $\mathrm{E}_{\text {cut }}$ & $4.46 \mathrm{E}-04$ & 1.7 & 5.9 & 3.3 \\
\cline { 2 - 6 } & TTB $+\mathrm{E}_{\text {cut }}$ & $4.56 \mathrm{E}-04$ & 1.6 & 8.3 & 1.0 \\
\hline \multirow{4}{*}{ Lead } & No bias & $1.27 \mathrm{E}-04$ & 3.5 & - & 23.2 \\
\cline { 2 - 6 } & TTB & $1.30 \mathrm{E}-04$ & 2.6 & 1.9 & 3.1 \\
\cline { 2 - 6 } & $\mathrm{E}_{\text {cut }}$ & $1.25 \mathrm{E}-04$ & 2.4 & -1.9 & 4.2 \\
\cline { 2 - 6 } & TTB $+\mathrm{E}_{\text {cut }}$ & $1.30 \mathrm{E}-04$ & 1.7 & 2.3 & 3.4 \\
\hline \multirow{4}{*}{ Steel } & No bias & $2.51 \mathrm{E}-04$ & 2.1 & - & 40.8 \\
\cline { 2 - 6 } & $\mathrm{TTB}$ & $2.50 \mathrm{E}-04$ & 1.1 & -0.3 & 15.5 \\
\cline { 2 - 6 } & $\mathrm{E}_{\text {cut }}$ & $2.53 \mathrm{E}-04$ & 1.7 & 0.7 & 8.2 \\
\cline { 2 - 6 } & $\mathrm{TTB}+\mathrm{E}_{\text {cut }}$ & - & 3.1 & - & - \\
\hline
\end{tabular}

\section{Conclusion}

The influence of the parameters implemented in RayXpert ${ }^{\circledR}$ is better known and transmission calculation for some basic configurations has been validated for the radionuclides most used in medical therapy facilities.

Regarding the gamma dose constant, there is an excellent agreement between RayXpert ${ }^{\circledR}$ and MCNPX for Ir-192 and Co-60. However, a significant difference ( $\sim \%$ ) appears for I-131, the value obtained with MCNPX corresponding to the one recommended by the DIN 6844-3 standard. This difference can be explained by the automatic definition by RayXpert ${ }^{\circledR}$ (default option) of the energy distribution of the fluence results $(\sim 7 \%)$ together with a small impact of the RayXpert ${ }^{\circledR}$ selection rule for the emission photon rays $(\sim 2-3 \%)$. For all radionuclides, the results are quite different from the values published in 1981 by the Oak Ridge National Laboratory.

There is an overall good agreement between RayXpert $^{\circledR}$ and MCNPX regarding transmission calculation: the relative difference between transmitted $\dot{\mathrm{H}}^{*}(10)$ is lower than $10 \%$ for the three radionuclides and all the investigated barrier materials and thicknesses.

Using the results obtained for transmission calculation, the cumulative tenth-value layer, $\mathrm{TVL}_{\mathrm{c}}$, and the successive tenth-value layers, $\mathrm{TVL}_{\mathrm{n}}$, were calculated for different typical shielding materials (ordinary concrete, lead, steel, brick and leaded glass). The values calculated with RayXpert ${ }^{\circledR}$ and MCNPX are in very good agreement, and are consistent with the data recommended by the IAEA SRS Report No. 47 (except $\mathrm{TVL}_{1}$ for concrete). On the other hand, significant discrepancies appear between our results and the values published by Delacroix for lead and steel.

The RayXpert ${ }^{\circledR}$ selection rule for the emission photon rays does not impact significantly the calculated ambient dose equivalent rate if it is applied in MCNPX.

Finally, biasing methods proposed in RayXpert ${ }^{\circledR}$ were checked (TTB approximation and energy-cutoff). They reduce significantly the calculation time and/or the statistical error, while having an impact on the results lower than $10 \%$, which is acceptable for radiation protection purposes.

This work should now be pursued along three major lines. Firstly, the calculations should be extended to other radionuclides encountered in medical facilities. Then the efficiency of RayXpert ${ }^{\circledR}$ should be tested for routine use and realistic configurations found in brachytherapy and nuclear medicine facilities. Finally, the possibility to use this software for radiology facilities should be studied.

\section{References}

1. RayXpert, Manuel d'utilisation (2014).

2. ICRP Publication 74, Conversion coefficients for use in radiological protection against external radiation (1996).

3. R.J. McConn Jr, C.J. Gesh, R.T. Pagh, R.A. Rucker, R.G. Williams III, Compendium of Material 
Composition Data for Radiation Transport Modeling, PNNL-15870 rev1 (2011).

4. MCNPX ${ }^{\mathrm{TM}}$ User's Manual Version 2.7.0 (2011).

5. ICRP Publication 107, Nuclear Decay Data for Dosimetric Calculations (2007).

6. IAEA Safety Reports Series Report No. 47, Radiation protection in the Design of Radiotherapy Facilities (2006).

7. Delacroix et al., Guide pratique Radionucléides et Radioprotection, 4ème édition, EDP Sciences (2004).

8. DIN 6844-3: 2006-12, Nuclear medicine departments - Part 3: Radiation protection calculations - Nuklearmedizinische Betriebe - Teil 3: Strahlenschutzberechnungen (2006).

9. L. M. Unger and D. K. Trubey, Specific GammaRay Dose Constants for Nuclides Important to Dosimetry and Radiological Assessment, ORNL/RSIC-45 (1981). 